\title{
Clinical Risk Assessment-Organizing Information Using Criminological Theory Seems to Work
}

\author{
Eva Lindström ${ }^{1}$, Mikael Olausson ${ }^{2}$, Eva Tuninger ${ }^{3}$ and Sten Levander ${ }^{4 *}$ \\ ${ }^{1}$ Department of Neurosience, Sweden \\ ${ }^{2}$ Forensic Psychiatric Clinic, Sweden \\ ${ }^{3}$ Clinical Sciences/Psychiatry, Sweden \\ ${ }^{4}$ Department of Criminology, weden \\ *Corresponding author: Sten Levander, Department of Criminology, SE 20510 Malmö, Sweden
}

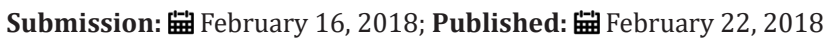

\begin{abstract}
Background: Risk assessment and management is a necessary and integrated part of clinical work. Risk assessment methods developed in the legal context differ from those traditionally used in clinical work but have been used to an increasing degree in such contexts.

Aim: In general, traditional clinical assessment methods can be improved by using structured instruments. With respect to risk management, wellestablished criminological theory is worth testing. EuRAX is a comprehensive and structured clinical risk management tool which integrates concepts from current criminological theories.
\end{abstract}

Method: 139 forensic psychiatric patients (stratified selection) were scored according to EuRAX.

Results: Scoring was rather problem-free given the rich documentation in Swedish forensic case history files. Construct and discriminant validity was good. The patients displayed a wide array of problems assumed to be associated with criminal propensity. The concepts of "social bonds" and "poor self-control", as operationalized in EuRAX, displayed meaningful and discriminant patterns with respect to the other EuRAX variables, and to HCR and PCL scores.

Conclusion: The use of well-established high-order criminological concepts, rated in a structured way, seems to provide important information relevant to the task of clinical risk management.

Keywords: Risk; Psychiatric diagnoses; Criminality; Violence; Forensic; Criminological theory

\section{Introduction}

Risk assessments have been the subject of controversies since the mid 1960ies. Before that, such assessments were essentially clinical and unstructured. The actual predictions turned out to be poor in the legal context once that was investigated. After a short period of risk assessment nihilism in the 1970ies, actuarial predictions were shown to have some promise. Clinical (here and now) and contextual factors (the future) were added in the $2^{\text {nd }}$ generation instruments like HCR-20 [1]. However, twenty years and many instruments later the predictive power (Area Under the Curve, AUC) rarely exceeds $75 \%$ of which $50 \%$ is the contribution from chance for dichotomous outcome measures [2-5]. The ability to predict rare events (like murder or suicide) is of course much worse. The question is whether risk assessments in its present form are clinically meaningful [6]. In contrast, it appears possible to identify risk in a short perspective with a high AUC using the Broset Violence Checklist [7].

Risk assessment in a wide meaning is a necessary ingredient in clinical work, and is no different from other clinical issues when a treatment plan is formulated and implemented. This clinical aspect must not be confused with risk assessment in a medico-legal context. Good clinical assessments combine structured methods with the clinician's tacit knowledge and clinical intuition, capitalizing on the immense pattern recognition competence of the human brain. The outcome of such risk assessments as a component of the general clinical work-up is a set of more or less immediately implemented interventions followed by a monitoring phase. Such clinical decision-making is therefore more than collecting information and following rules, it is a process over time. Poor prediction on the individual level is not a reason to abstain from clinical risk reducing interventions [8].

Only rarely do we need to administer interventions against the will of the patient. When this is necessary we have to change hat and perform a medico-legal assessment, according to legal frameworks which are different from country to country, and surrounded by poorly defined grey zones. Then, structured instruments should be used.

The clinical mission is multi-facetted. There are no simple cause-effect relations in the clinic-one intervention will usually 
have a range of effects. By addressing the risk of violence successfully we will most likely attain a reduction in victimization, paranoid attitudes vs. others and an increase in prosocial activities [9-11]. This argument can be turned around-many interventions will reduce acting-out, as a "side-effect". A good way to reduce victimization is to restore or at least increase the social competence of such patients. This requires identification of remediable components which are linked to the reduced competence. Poor social skills precipitate interpersonal conflicts which can develop into confrontations. Psychiatric patients usually come out as victims rather than offenders from such confrontations. Addressing treatment needs linked to reduced social competence is therefore not only positive with respect to the patients' Quality of Life; it is crime preventive as well.

The current practise of risk assessment in the clinic has been strongly influenced by the development of risk instruments in a legal context. The rationale for such instruments is to maximize prediction (specificity and sensitivity) at a specific point in time, and for a defined time-span into the future. Consequently, focus is on statistically significant risk and protective factors rather than generative mechanisms in such work [12]. Understanding mechanisms is a prerequisite for the selection of successful clinical interventions-risk factors may be merely correlates. And, as stated above, there is a growing awareness that we will never reach even modest goals with respect to the predictive power of risk assessments on the individual level.

Furthermore, such instruments are alien to the way clinicians think and work. Clinical risk assessments as performed up to 1970 did not deliver. The knowledge-base of criminology and psychiatry has grown considerable since then. With respect to psychiatry, the DSM-III way of defining diagnoses in 1980 was a major step towards honouring structured assessment and respecting empirical findings. Clinical work has changed dramatically in the wake of the DSM-III -IV and -V (2014) versions. Criminological theory has undergone a corresponding development, replacing one-factor theories Hirschi [13] with integrated models [14-16]. It should be possible to re-introduce "subjective" elements (tacit knowledge) in clinical risk management work (Structured Professional Judgement and Professional over-ride) if we are able to combine current models from psychiatry and criminology when developing new risk assessment instruments. Over time the growth of the knowledge base and reasoning skills that can be expected from a wide-spread use of such instruments will improve clinician's skills [4,17-20].

Over the last 20 years our group has developed a set of clinical assessment instruments with some applicability for risk assessments. One point of departure has been the involvement of all agents, including the patients, in the assessment work. Therefore, a set of self-assessment methods (computerized or paper \& pencil) have been developed [21,22]. The clinical assessments are to a large extent intended for use by staff with short formal education (assistant nurses) because they spend much more time with individual patients than psychologists/ psychiatrists [22]. Clinical assessments should be different for the different phases of treatment-from acutely ill inpatients to outpatients well on the road towards recovery. Most of the instruments should be of a monitoring or screening kind-with possibilities for individualization. However, there must also be a "top of the line" expert instrument. A preliminary version of such an instrument, the EuroCog Risk Assessment eXpert instrument (EuRAX) was conceived in 1997 and developed into its current form in 2008. From the beginning, the integrated criminological theory governed the thinking, in line with Eric Silver's (2006) call for a criminological perspective in tomorrow's risk instruments $[14,16]$. However:

Criminology is a fragmented discipline and its key theoretical and empirical insights are poorly integrated. This state of affairs hampers the development of a sound understanding of crime and hinders advancement of effective crime prevention strategies and policies. Situational Action Theory (SAT) was developed to overcome key short-comings [16].

As a criminological theory, the SAT is specifically suited to contribute a theoretical, causally oriented framework to the essentially a-theoretical risk assessments according to the Intuitive clinical and the Structured Professional Judgement approaches [23]. In SAT, individuals are characterized with respect to attachment, obligations, belief in conventional values, self-control and (the last addition) morality. There has been a massive increase in moral cognition studies in the last few years, for good reasons $[24,25]$. Empirical findings in recent criminological research suggest that morality is perhaps the strongest individual factor of all determining if a person will commit a crime or not [26,27].

It should be noted that the criminological SAT concepts differ from the same-named concepts defined in psychology-for instance "Self-control". Morality in SAT is assessed by self-reports to "is it right to..." items (moral principles), moral dilemmas (short vignettes and a number of alternatives), and if they experience shame and guilt. Compassion is assessed as a facet of self-control. The criminological and psychological traditions should benefit by creating unified definitions/operationalizations.

\section{Aims}

The data of the present report was collected among patients subjected to a court-ordered forensic psychiatric assessment at the Malmö University Hospital (U-MAS). The first aim was to characterize the forensic material with respect to conventional clinical attributes like sex, age, social back-ground, diagnoses, and criminality, expecting clinically non-significant correlations between criminality and most of such variables. The second aim was to find out if alternative risk-relevant attributes could be assessed in a meaningful way, and the frequency of such problems.

A third aim was to try to identify patterns of associations among the variables which were linked to conventional characteristics like diagnoses, and could be used to construct clinically meaningful clusters of individuals. The last aim was to link single and aggregated variables to scores of the standard risk instrument HCR-15, and to psychopathy. 


\section{Method}

\section{Subjects}

Eligible subjects were all patients $(\mathrm{N}=850)$ subjected to a courtordered forensic psychiatric assessment at the Department of the Forensic Psychiatry (Malmö University Hospital U-MAS), during the years 1992 to 2006. Among those, 120 patients were selected to obtain a reasonably representative set of all forensic assessments according to the following principles:

1) Index crime-violent/non-violent (most patients committed violent crimes)

2) Enough patients who committed arson and sexual crimes (over-sampling)

3) Whether the patient was on remand or not (over $80 \%$ are remand patients assessed as inpatients, non-remand patients are assessed as out-patients).

4) Diagnosed as suffering from a serious mental disorder or not (a concept defined in the Swedish penal code, which is substantially wider than the "Not Guilty Reason Insanity" clause of the legal code of other countries)-around $45 \%$ of the cases are assessed as suffering from such a disorder.

The actual selection of the patient material was done by a secretary at the clinic, who was informed about the principles of the selection but otherwise did it himself, without any intervention from the researchers. In addition, 19 Swedish forensic patients who took part in another study were included, the After Care patients [28]. These patients were released from compulsory treatment at the clinic during the years 1998 to 2002, subjected to a very detailed assessment at that point in time, and were then followed with new assessments each half year for two years, and then finally after five years.

Among the patients there were 19 women and 120 men. Age varied from 15 to 72 with a mean of 35. Sixty percent were Swedishborn, 13\% had West European background, 17\% East European, 8\% Middle East and 2\% other origin.

\section{The EuRAX Instrument}

This instrument was conceived in an early form by the senior author (SL) in 1997. The aim was to construct a more clinically oriented instrument than the contemporary ones, for instance HCR-20, published a few years earlier [1]. One point of departure was modern criminological theory specifically the Social bonds theory with its three facets (Attachment, Commitment and Belief), combined with Poor self-control morality and the Life-course perspective $[14,16]$.

Risk may be associated with trait-like attributes (habitual risk) or state-like conditions (episodes). A schizophrenic patient might be completely non-aggressive and socially withdrawn between the psychotic episodes, but very aggressive during acute episodes. Another kind of ego-dystonic violence is represented by deviant drug reactions. There are also other kinds of time-limited states (post-ictal psychoses, dissociative states) which can be associated with violent acting-out. For these cases, the clinical task is to prevent new acute episodes to occur or help the patient to abstain from the drug which caused the deviant reaction. For patients with habitual or trait-like causes of violence, the task is to help the patient to cope with her/his more or less constant proneness to use violence in many situational contexts. Thus, risk assessment/ management should consider these problems separately.

An increased risk may be associated with certain but not very common symptoms or signs [6]. Clinical examples of such attributes are reports of sexual or aggressive and sometimes sadistic fantacies which often have an obsession-like taint, like those specified in the Scale of Evil [29]. Likewise, a substantial lack of empathy, either as a consequence of the "theory of mind" problems characteristic of autism spectrum disorders [30], or little or no compassion for others, as among psychopaths, is probably associated with a higher rate of violent crimes, all other factors equal. Rare causes of violent acts will never contribute significantly to the prediction power for future violence. Clinically such problems must be addressed regardless of prediction possibilities.

As part of the program for EuRAX, we believe that the information inherent in low-level risk attributes (like impulsiveness, poor affect control and lack of judgment and insight) should be possible to organize under the umbrella of high-level constructs, partly just to organize thinking but also because good high-level constructs (other than diagnoses) summarizes important aspects. Such organizing concepts are for instance a subdivision of violence into impulsive/affective, predatory and psychotic violence [18] Contemporary sociologically oriented criminology has developed a set of constructs which have a substantial empirical backing-up [16]. It appeared enigmatic to us as well as to Silver (2006) that such constructs have not been included in risk assessment instruments, neither then nor up to now.

EuRAX is a very comprehensive instrument, still to some extent in the making. It cannot be fully presented within a scientific journal paper. Complete Swedish and English versions can be down-loaded (or inspected) from the Home page of Cognitive Science Holding. The information to consider, before scoring EuRAX, is obtained via case history files (the more, the better), and a PCL type semistructured interview Hare [31], which is always longer than one hour, and typically two or more hours. It is semi-structured because there are a fixed set of topics to cover, and still the patient must be provided with enough time and freedom to "present" her/ himself. The interviewer starts as an interested listener but may become more confrontatory towards the end of the interview. Many items can be rated on the basis of file information. Other items, for instance the five conscience/morality items, require an interview. The scoring format for most of the variables is the same as for PCL/R and HCR-20: 0, 1 or 2.

\section{Rating Procedure}

The EuRAX scoring was limited to case history file data, no interviews were done. All available material was used, i.e., the set 
of forensic assessments (usually two, a pretrial one and a detailed full assessment), actual sentences, and the hospital records of the patients. A Swedish forensic assessment is produced as a teamwork: a forensic psychiatrist, a psychologist, a social worker and a nurse, and usually summarizes three weeks of "around-the-clock" observations and many interviews. The first author (MO) scored the forensic assessments of all included patients. The EuRAX went through some changes during the time period of the scoring workactually, each patient was rescored twice because of revisions.

HCR-15 and psychopathy checklist data (PCL/R or PCL/SV) were available for a subset of subjects-obtained in association with a forensic assessment and performed by other and independent clinicians.

\section{Statistics}

Standard statistical procedures were employed using SPSS 22, except with respect to a cluster analyses for which the Latent Gold non-parametric cluster procedure was used [32]. 'Effect size' refers to Cohen's d statistic (Cohen, 1977).

\section{Ethics}

The study is covered by two approvals, one specifically for the AfterCare study (Sheilagh Hodgins) and a more general one concerning research at the Department of Forensic Psychiatry (Henrik Anckarsäter).

\section{Results}

\section{Subject's background}

Table 1: Childhood adverse conditions, percentages.

\begin{tabular}{|c|c|c|c|}
\hline & No Problems & Some & Distinct \\
\hline Stability & 47 & 33 & 20 \\
\hline Quality & 52 & 38 & 10 \\
\hline Stressors & 37 & 45 & 18 \\
\hline Parents & No & Yes & \\
\hline Abuse & 73 & 26 & \\
\hline Psychiatric & 85 & 15 & \\
\hline Outcasts & 91 & 9 & \\
\hline Placement & 71 & 29 & \\
\hline
\end{tabular}

The background of the patients was scored with respect to three dimensions: stability, quality and stressors. Furthermore, their parent's abuse, psychiatric problems and being social outcasts was noted, and whether the patient had been placed in institution or foster-home during childhood. Such problems were very common, as shown in Table 1 . The seven variables had an intraclass correlation of 0.84 . A compound childhood disadvantage score was computed as the sum of six of the variables adding placement outside the family with double weight. The distribution of the childhood adverse scores is shown in Figure 1. Among the patients over age 24 , only $25 \%$ had been married but $53 \%$ had at least one child.

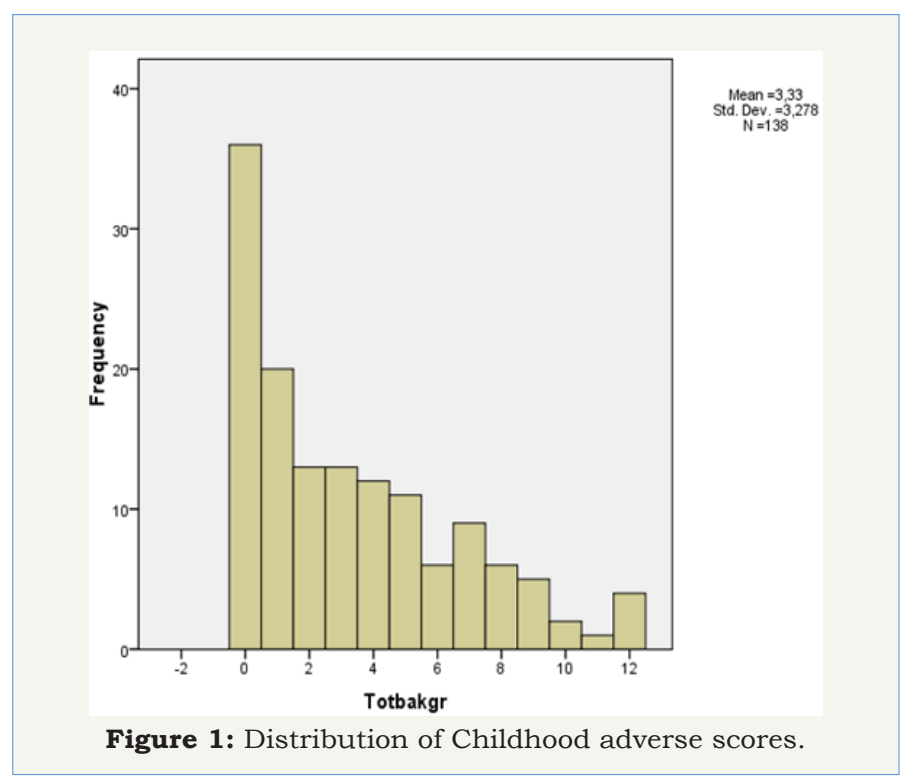

Criminality

Table 2: Index crime of 139 patients who underwent a forensic psychiatric assessment at U-MAS.

\begin{tabular}{|c|c|c|}
\hline Murder & 17 & $12 \%$ \\
\hline Other serious violence & 25 & $18 \%$ \\
\hline Robbery & 11 & $8 \%$ \\
\hline Arson & 11 & $8 \%$ \\
\hline Sexual crimes & 12 & $9 \%$ \\
\hline Drug related crimes & 19 & $14 \%$ \\
\hline Other crimes & 44 & $31 \%$ \\
\hline
\end{tabular}

The index crime (salient categories) is listed in Table 2. Of those, 106 were crimes involving violence. In addition to the index crime, $59 \%$ of the patients were sentenced for other crimes $(28 \%$ two crimes, $14 \%$ three crimes, $17 \%$ more than three crimes). There were no sex effects for any of these variables (except sex crimes, all were men). The index criminality was to only a moderate extent representative of previous criminality, e.g., violence/ violence: $\mathrm{X}^{2}=3.85, \mathrm{p}=.05$ and sex/sex: $\mathrm{X}^{2}=6.47, \mathrm{p}<.05$. A large majority of the patients were charged with crimes of violence, either as the index crime (37\%) or previously (39\%). Of the 32 patients $(23 \%)$ who committed non-violent index crimes, 8 (6\%) had committed previous crimes of violence leaving 24 patients (17\%) free of lifetime violent crimes (as far as we know).

\section{Characterization of criminality}

The patients were classified with respect to onset of criminality (up to age 18, between 19 and 24, and >24) and activity: no previous sentences (before the index crime), one, 2 to 3 , and more than 3 previous sentences. The distribution of patients in these categories is shown in Table 3. There was a fairly strong correlation (tau = .38) between age at the first sentence and being criminally active, in line with the Moffitt typology category "life-course persistent criminals" [33]. 
Table 3: Characterization of the 139 patients with respect to onset of criminality and life-time criminal activity.

\begin{tabular}{|c|c|c|c|c|}
\hline & \multicolumn{5}{|c|}{ Age at First Sentence } \\
\hline Number of sentences & Before 19 & $\mathbf{1 9 - 2 4}$ & After 24 & Total \\
\hline Only the Index crime & 5 & 6 & 29 & 40 \\
\hline One previous sentence & 4 & 7 & 7 & 13 \\
\hline $2-3$ previous sentences & 7 & 5 & 9 & 25 \\
\hline$>3$ previous sentences & 24 & 21 & 54 \\
\hline
\end{tabular}

\section{Diagnoses}

Table 4: Diagnoses of 139 forensic psychiatric patients. Cluster group refers to increasing abuse problems, see text.

\begin{tabular}{|c|c|c|c|c|c|c|c|}
\hline \multirow[b]{3}{*}{ Schizophrenia } & \multirow{2}{*}{\multicolumn{2}{|c|}{ Co-Morbid Abuse }} & \multicolumn{5}{|c|}{ Abuse Cluster Groups } \\
\hline & & & \multirow{2}{*}{$\begin{array}{c}\mathbf{1} \\
21 \% \\
\end{array}$} & \multirow{2}{*}{$\begin{array}{c}\mathbf{2} \\
25 \% \\
\end{array}$} & \multirow{2}{*}{$\begin{array}{c}\mathbf{3} \\
36 \%\end{array}$} & \multirow{2}{*}{$\begin{array}{c}\mathbf{4} \\
7 \%\end{array}$} & \multirow{2}{*}{$\begin{array}{c}\mathbf{5} \\
11 \% \\
\end{array}$} \\
\hline & $20 \%$ & $54 \%$ & & & & & \\
\hline Other psychoses & $14 \%$ & $47 \%$ & $23 \%$ & $9 \%$ & $27 \%$ & $18 \%$ & $18 \%$ \\
\hline Neuropsychiatric & $12 \%$ & $25 \%$ & $44 \%$ & $31 \%$ & $0 \%$ & $19 \%$ & $7 \%$ \\
\hline Abuse & $12 \%$ & --- & & & & & \\
\hline Personality disorders & $42 \%$ & $68 \% * *$ & $22 \%$ & $16 \%$ & $19 \%$ & $29 \%$ & $14 \%$ \\
\hline Cluster A & $4 \%$ & $100 \%$ & too few & & & & \\
\hline Antisocial & $16 \%$ & $73 \%$ & $18 \%$ & $23 \%$ & $36 \%$ & $9 \%$ & $13 \%$ \\
\hline Borderline & $9 \%$ & $67 \%$ & $8 \%$ & $25 \%$ & $17 \%$ & $33 \%$ & $17 \%$ \\
\hline Other & $13 \%$ & $61 \%$ & $36 \%$ & $14 \%$ & $5 \%$ & $36 \%$ & $9 \%$ \\
\hline No diagnosis & $10 \%$ & --- & & & & & \\
\hline
\end{tabular}

The diagnoses of the patients are presented in Table 4. The most notable finding is the high frequency of co-morbid abuse, in almost all diagnostic categories.

According to own unpublished data on more than 2000 Swedish pretrial forensic assessments, involving violence and alcohol, deviant alcohol reactions appear to be associated with approximately $15 \%$ of the crimes of violence. Such reactions are also commonly reported (30\%) by Swedish prison inmates [34]. In the present material 42 (30\%) patients reported such experiences. These data will be reported separately.

Problems listed under Axis IV (psycho-social stress) were common and often multiple. Sixteen percent of the patients had no relevant Axis IV diagnosis, 28\% had at least one type of problems, $37 \%$ had two problems and $19 \%$ had three or more problems. Problems in the social network were most common (45\%) followed by economy, work, housing (37\%), primary group (32\%), and victimization, separations and abusing friends (all 15\%).

The GAF (Global Assessment of Function) scores at the time of forensic assessment varied between 10 and 90 with quartile values 34, 43 and 54. Schizophrenic patients had a mean GAF of 37 , and those with no diagnosis 59. The association between GAF scores (which reflect symptoms/suffering and social functioning) and Axis IV problems were analyzed by independent t-tests. Low GAF scores were marginally associated with fewer problems in the primary group but more problems in the social network. There was no correlation between the total number of Axis IV problems and GAF scores.

\section{Childhood adverse conditions, diagnoses and criminality}

The association between childhood adverse conditions and the main diagnosis was explored by independent t-tests. Only two analyses, both referring to personality disorders were significant: Antisocial $(\mathrm{p}<.05$, effect size 0.6$)$ and Borderline $(\mathrm{p}<.001$, effect size 1.0). The corresponding analyses vs. criminality were all nonsignificant.

\section{Suicide/self-harm and victimization/victims history}

Suicide thoughts, plans and actual suicide acts were common. At least one act was reported by $33 \%$, repeated acts by $13 \%$. Suicide had been considered at least once by $59 \%$. Acts of self-harm without suicide intent was reported by $19 \%$. The rate of victimization was also high: $33 \%$ of the patients had been abused by close relatives, $15 \%$ by people they knew and $30 \%$ had been abused by strangers.

The violence of the patients had been directed towards close relatives in $46 \%$ of the cases, towards people they knew in $41 \%$ of the cases and towards strangers in $53 \%$ of the cases. There were no significant associations among the three victimization measures, but a rather strong association between violence against acquaints and strangers $(\mathrm{p}<.01)$. Across the sets of variables, only one significant association emerged: being abused by acquaints was associated with violence against acquaints $(\mathrm{p}<.05)$. Thus, family 
violence was specific and not associated with any other category of violence against others.

Exposure to family violence predicted self-harm $(\mathrm{p}<.05)$ but not suicide. Exposure to violence from others predicted neither suicide, nor self-harm.

\section{Low-level risk-relevant indices}

The base rate with respect to the kind/motivation of violent acts is displayed in Table 5.

Table 5: Axis IV psychosocial problems which contributed to the Axis I and II diagnoses.

\begin{tabular}{|c|c|}
\hline Problems in the social network & $45 \%$ \\
\hline Problems with economy, work, housing & $37 \%$ \\
\hline Problems in the primary group & $32 \%$ \\
\hline Exposure to stress - PTSD type & $16 \%$ \\
\hline Separations & $16 \%$ \\
\hline Friends with abuse problems & $14 \%$ \\
\hline & \\
\hline
\end{tabular}

As can be deduced from the percentages, multiple types were common among the patients who had at least one significant criminal act of violence. The base rate reflecting certain attributes of the criminality (rational/irrational, impulsive, ego-syntonic, drug-induced disinhibition, deviant personality, chronic psychosis, acute psychotic episodes and dissociation) is shown in Table 6, rated ad modum PCL/R.

Table 6: Percentages of types of aggressive criminal acts among 139 forensic patients, and characteristics of the four cluster groups based on types of aggression.

\begin{tabular}{|c|c|c|c|c|c|}
\hline \multirow{2}{*}{ Aggression type } & \multirow{2}{*}{ Frequency } & \multicolumn{4}{|c|}{ Cluster group problems } \\
\hline & & A & B & $\mathbf{C}$ & $\mathbf{D}$ \\
\hline Instrumental & $50 \%$ & 0 & 1 & 1 & 0 \\
\hline Irritable & $45 \%$ & 0 & 1 & 0 & 1 \\
\hline $\begin{array}{l}\text { Offensive } \\
\text { affective }\end{array}$ & $21 \%$ & 0 & 0 & 0 & 1 \\
\hline $\begin{array}{l}\text { Defensive } \\
\text { affective }\end{array}$ & $4 \%$ & 0 & 0 & 0 & 0 \\
\hline $\begin{array}{c}\text { Territorial } \\
\text { defense }\end{array}$ & $41 \%$ & 0 & 0 & 1 & 1 \\
\hline Status defense & $40 \%$ & 0 & 0 & 1 & 0 \\
\hline Partner & $25 \%$ & 0 & 1 & 0 & 0 \\
\hline Frustration** & $17 \%$ & 0 & 0 & 0 & 0 \\
\hline Cluster group N & & 40 & 27 & 43 & 29 \\
\hline
\end{tabular}

A cluster analysis of the degree of rationality/being egosyntonic for the crimes (Table 6) suggested that a 3-cluster solution was reasonable: a Psychotic subgroup ( $\mathrm{N}=39)$, an Antisocial subgroup $(\mathrm{N}=55)$ and an Other Disorders subgroup $(\mathrm{N}=45)$. The profile of the data of the three clusters is shown in Figure 2.

One important concept in modern criminological theory is poor self-control. In the EuRAX instrument this concept is operationalized as a set of relevant key personality characteristics like impulsiveness, affect control and executive competence (Table 7). The high frequency of problems is note-worthy.
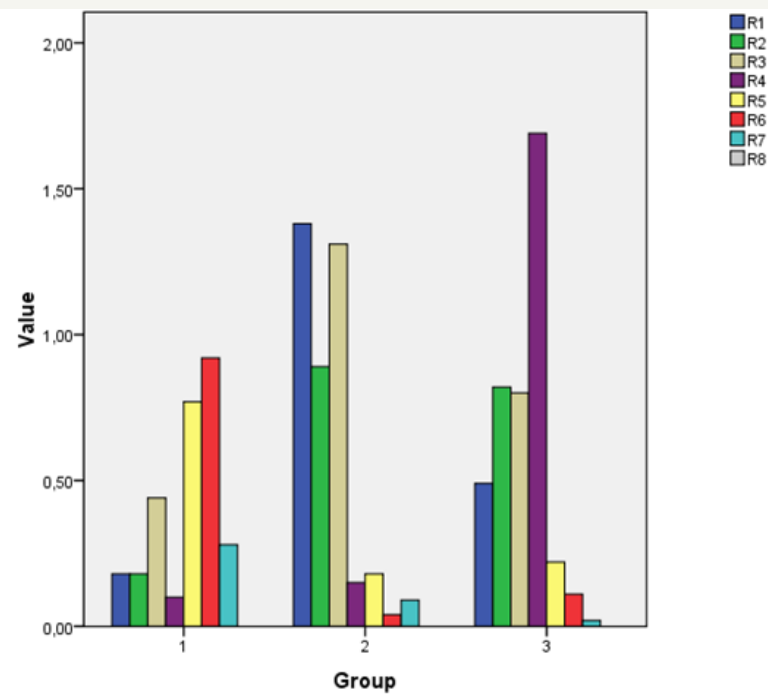

Figure 2: Characteristics of the crimes with respect to rationality/being ego-syntonic (Table 7 ) for three cluster analysis derived groups of patients, denoted

1. Psychotic

2. Antisocial

3. Other personality disorders

Table 7: Percentages of certain attributes of the cumulated criminal history of 139 forensic patients. Scores 0.2 are of the $\mathrm{PCL} / \mathrm{R}$ type (increasing fit).

\begin{tabular}{|c|c|c|c|c|c|}
\hline Score & $\mathbf{0}$ & $\mathbf{1}$ & $\mathbf{2}$ & Rationality & Ego-syntonic \\
\hline Rational & $52 \%$ & $21 \%$ & $27 \%$ & yes & yes \\
\hline Impulsive & $53 \%$ & $28 \%$ & $19 \%$ & yes & yes \\
\hline $\begin{array}{c}\text { Drug-induced } \\
\text { disinhibition }\end{array}$ & $44 \%$ & $22 \%$ & $34 \%$ & yes & yes \\
\hline $\begin{array}{c}\text { Non- } \\
\text { psychotic } \\
\text { personality } \\
\text { deviance }\end{array}$ & $59 \%$ & $19 \%$ & $22 \%$ & doubtful & yes \\
\hline $\begin{array}{c}\text { Chronic } \\
\text { psychotic }\end{array}$ & $74 \%$ & $16 \%$ & $10 \%$ & no & yes \\
\hline $\begin{array}{c}\text { Psychotic } \\
\text { episode }\end{array}$ & $76 \%$ & $17 \%$ & $7 \%$ & no & no \\
\hline $\begin{array}{c}\text { Dissociation } \\
\text { episode }\end{array}$ & $89 \%$ & $9 \%$ & $2 \%$ & no & no \\
\hline
\end{tabular}

\section{High-level criminological characterization}

The social bonds theory specifies three dimensions which are predictive of criminal propensity: attachment, commitment and conscience/belief in the conventional order $[14,16]$. Attachment and Commitment is covered by two variables. Belief is covered by one index reflecting compassion and one group of five items reflecting conscience, shame and guilt. The conscience measures are not possible to rate without having access to interview data and are not presented here. 
As many as $81 \%$ of all the patients had deficits with respect to Commitment and $72 \%$ were lacking in Attachment. Considerably fewer $(37 \%)$ had deficits with respect to Compassion. Attachment and Commitment were strongly associated $(\mathrm{tau}=.48, \mathrm{p}<.001)$. Being immigrant was not associated with any of the variables. Lack of compassion was associated with Attachment/ Commitment, but less strongly ( $\operatorname{tau}=.22, \mathrm{p}<.001)$.

The sum of Attachment and Commitment scores was run vs. relevant variables using one-way ANOVAs for analog variables and by cross-tabulation vs. categorical data using $\mathrm{X}^{2}$ or Kendall's tau as statistics. Poor attachment/ commitment was differentially associated with an array of the other variables: schizophrenia, poor social network, parents having had abuse problems, but no other childhood adverse conditions, poor social network but no other
Axis IV problems, violence more often against strangers but not partners, motivated by frustration, impulsive or pseudo-rational (chronic psychotic type), linked more to abuse of cannabis and amphetamine than alcohol, and strongly linked with several aspects of poor self-control.

In contrast, Compassion displayed a complex pattern vs. the other variables-the strongest $(\mathrm{p}<.01)$ being obtained for Manslaughter (but not serious violence), Antisocial personality disorder, Abuse of acquaints and Impulse/Affect control.

Summing up, Attachment/Commitment and Compassion displayed rather different patterns of associations with the other EuRAX variables, suggesting differential validity, in spite of the fact that the two measures were modestly correlated (Table $8 \& 9$ ).

Table 8: Percentages of problems reflecting self control functions. Scores $0.2=$ increasing problems. Cluster groups refer to a 4-cluster solution for self-control (see text).

\begin{tabular}{|c|c|c|c|c|c|c|c|}
\hline \multirow{2}{*}{ Score } & \multirow{2}{*}{$\mathbf{0}$} & \multirow{2}{*}{1} & \multirow{2}{*}{2} & \multicolumn{4}{|c|}{ Mean Cluster group problems } \\
\hline & & & & A & B & C & D \\
\hline Impulsiveness & 51 & 19 & 29 & 0.71 & 0.32 & 1.04 & 0.99 \\
\hline Stimulus seeking, monotony avoid. & 66 & 21 & 14 & 0.14 & 0.29 & 0.96 & 0.48 \\
\hline Affective control frustration tolerance & 29 & 42 & 30 & 0.21 & 0.44 & 0.93 & 1.01 \\
\hline Intelligence & 83 & 15 & 2 & 0.81 & 0.03 & 0.16 & 0.19 \\
\hline Executive functions & 45 & 32 & 22 & 1.79 & 0.35 & 0.33 & 0.77 \\
\hline Insight & 30 & 40 & 30 & 1 & 0.35 & 1.62 & 1.01 \\
\hline Treatment adherence & 28 & 39 & 33 & 0.64 & 0.26 & 1.6 & 1.05 \\
\hline Cluster group $\mathbf{N}$ & & 14 & 34 & 45 & 46 & & \\
\hline
\end{tabular}

Table 9: Associations between self-control cluster groups (A to D) and a relevant subset of the EuRAX indices. Over/Under signifies which group that contributed to the significant X2/F-value.

\begin{tabular}{|c|c|c|c|c|}
\hline \multirow{3}{*}{ Index criminality } & \multirow{2}{*}{$\begin{array}{l}\text { Significant } \\
\text { Violent*** }\end{array}$} & \multicolumn{2}{|c|}{ Over/ Under } & \multirow{2}{*}{$\begin{array}{c}\text { Non-significant } \\
\text { Murder, Serious violent, Sexual }\end{array}$} \\
\hline & & & A & \\
\hline & Arson** & A & $\mathrm{C}$ & Robbery, Drug related, Other \\
\hline \multirow{5}{*}{ Life history criminality } & Violent crimes*** & C, D & A, B & Sexual, Drug-related \\
\hline & Property crimes* & C, D & B & \\
\hline & Arson** & C, D & A, B & \\
\hline & Age at $1^{\text {st }}$ crime* & A and B older & & \\
\hline & Previous sentences* & B fewer & & \\
\hline \multirow{4}{*}{ Diagnoses, Axis I and II } & Other psychoses* & $\mathrm{C}$ & D & Schizophrenia, Abuse \\
\hline & Neuropsychiatric* & A & & No diagnosis \\
\hline & Personality dis.* & $\mathrm{D}$ & B & Borderline \\
\hline & Antisocial** & $\mathrm{C}$ & A, B & Other pers.dis. \\
\hline Axis IV & None & & All indices & \\
\hline Axis V & $\operatorname{GAF}(-)^{* * *}$ & B higher & & \\
\hline Childhood stressors & None & & All indices & \\
\hline Being victimized & None & & All indices & \\
\hline Suicide, selfharm & Suicide* & $\mathrm{D}$ & & Self-harm \\
\hline
\end{tabular}




\begin{tabular}{|c|c|c|c|c|}
\hline \multirow{3}{*}{ Who was the victim } & Family*** & $\mathrm{D}$ & & \\
\hline & Acquaints** & C, D & A, B & \\
\hline & Strangers** & C, D & A, B & \\
\hline \multirow[t]{3}{*}{ Character of violent crimes } & Instrumental** & $\mathrm{C}, \mathrm{D}$ & $\mathrm{A}, \mathrm{B}$ & Affective/offensive \\
\hline & Irritable** & $\mathrm{D}$ & & Territorial, Partner \\
\hline & Status defence** & $\mathrm{C}$ & $\mathrm{A}, \mathrm{B}$ & Frustration \\
\hline \multirow{4}{*}{ Rationality of crimes } & Impulsive*** & $\mathrm{D}$ & & Instrumental \\
\hline & Chronic psych.*** & $\mathrm{C}$ & B & Drug disinhibition \\
\hline & & & & Serious Pers. Disorder type \\
\hline & & & & Episode related \\
\hline Abuse & Amphetamine*** & $\mathrm{C}$ & B & Alcohol, Cannabis \\
\hline
\end{tabular}

+ to ${ }^{* * *}$, significance $\mathrm{p}<.10$ to $\mathrm{p}<.001$.

\section{HCR-15 and psychopathy in relation to the EuRAX variables}

HCR data were available for 76 subjects. The aggregated indices SumH and SumC was obtained by summing all $\mathrm{H}$ items except $\mathrm{H} 6$ (mental illness) and summing all $\mathrm{C}$ items except $\mathrm{C} 3$, in order to obtain a reasonably high homogeneity among the summed items.

Psychopathy ratings were performed using either PCL/R (20 items) or PCL/SV (12 items). For some patients only the HCR item $\mathrm{H} 7$ was available as an index of psychopathy. All ratings were transformed to the same format, i.e., rated as 0,1 or 2 . Such data were available for 112 subjects with the following distribution, 0 (52\%), 1 (35\%) and 2 (13\%). The variables were intercorrelated: PCL vs H (.68) and C (.38). The H and C correlation was .40.

Stepwise linear regression analyses were performed for a large subset of theoretically relevant EuRAX variables as predictors, on PCL (scored 0,1 or 2), the sum of the H items (except item H6) and the sum of the $\mathrm{C}$ variables of HCR-15.

Psychopathy was predicted by 9 variables yielding $\mathrm{R}=0.86$. In the following, Kendall's tau inter-correlations higher than $.24(\mathrm{p}<.01)$ are listed rather than presenting the actual variables selected by the regression procedure (a highly uncertain procedure with all the co-linearities inherent in the data set). These variables were: Lack of Compassion (.57); Evilness (.52), Age at first crime (-.40); Rational crimes (.37); Age $1^{\text {st }}$ sentence (-.36); Perpetrator violence against an acquaint (.30) and a Stranger (.29); Number of previous sentences (.29); Exposed to violence from acquaint (.28); Impulsive crimes (.26); Defence of status (.26) and Instrumental criminality (.25).

H scores were predicted by 19 variables yielding $\mathrm{R}=.90$. The strongest predictors (Kendall's tau) were Age at 1st sentence (-.63); Age at 1st crime (.61) and Number of previous sentences (.55), reflecting previous criminality. Strong predictors were Commitment (.48), Attachment (.31), Compassion (.42) and Evilness (.35), i.e. social concepts belonging to the integrated criminological theory, and social background: Stability $(0.40)$ and Problems during upbringing (.33). Criminality was Rational (.44); Impulsive (.48); Disinhibited (.30); Instrumental (.34) and involved Defence of Status (.33). Personality factors were Impulsivity (.35); need for Strong stimuli (.36); and poor Affect control (.32). High
$\mathrm{H}$ subjects had been exposed to violence by kin (.30) or strangers (.33) and abused acquaints (.37) and strangers (.51).

In contrast, $\mathrm{C}$ variables were to a smaller extent correlated with the EuRAX variables. The $\mathrm{R}$ of the regression procedure was .56 based on three variables. The strongest predictors were Commitment (.35), Compassion (.46) and Evilness (.36). Notable is the correlation between SumC and abuse of kin (.35) (Table 10).

Table 10: Associations between Attachment/Commitment and a relevant subset of the EuRAX indices.

\begin{tabular}{|c|c|c|}
\hline & Significant & Non-significant \\
\hline \multirow{3}{*}{ Index criminality } & Murder* & Sexual \\
\hline & $\begin{array}{l}\text { Serious violent } \\
\text { crimes + }\end{array}$ & Arson \\
\hline & Robbery* & Other \\
\hline \multirow{3}{*}{ Life history criminality } & Violent crimes $^{* * *}$ & Sexual \\
\hline & $\begin{array}{c}\text { Age at } 1^{\text {st }} \text { crime } \\
(-)^{* *}\end{array}$ & Drug-related \\
\hline & & Property \\
\hline \multirow{3}{*}{ Diagnoses, Axis I and II } & Schizophrenia*** & Other psychoses \\
\hline & NoDiagnosis $(-)^{* *}$ & Abuse \\
\hline & & $\begin{array}{l}\text { Personality disorder } \\
\text { (any) }\end{array}$ \\
\hline Axis IV & Social network ${ }^{* * *}$ & All other categories \\
\hline Axis V & $\operatorname{GAF}(-)^{* * *}$ & \\
\hline \multirow{3}{*}{ Childhood stressors } & Parents' abuse** & $\begin{array}{l}\text { Parents psychiatric } \\
\text { problems }\end{array}$ \\
\hline & & Family social outcasts \\
\hline & & $\begin{array}{l}\text { Foster home/ } \\
\text { institution }\end{array}$ \\
\hline Being victimized & None & All three indices \\
\hline Suicide, selfharm & None & All indices \\
\hline \multirow{2}{*}{ Who was the victim } & Stranger*** & Family member \\
\hline & & Acquaints \\
\hline \multirow[t]{2}{*}{$\begin{array}{l}\text { Character of violent } \\
\text { crimes }\end{array}$} & $\begin{array}{c}\text { Partner violence } \\
\qquad(-)^{* *}\end{array}$ & All other categories \\
\hline & Frustration* & \\
\hline
\end{tabular}




\begin{tabular}{|c|c|c|}
\hline \multirow{3}{*}{ Rationality of crimes } & Impulsive*** & Instrumental \\
\hline & $\begin{array}{c}\text { Chronic } \\
\text { psychotic*** }\end{array}$ & Drug related \\
\hline & & Episode related \\
\hline \multirow[t]{2}{*}{ Abuse } & Cannabis*** & Alcohol \\
\hline & Amphetamine ${ }^{* * *}$ & \\
\hline \multirow{5}{*}{ Self-control } & Impulsive*** & Monotony avoidance \\
\hline & Affective control* & IQ \\
\hline & $\begin{array}{c}\text { Executive } \\
\text { competence** }\end{array}$ & \\
\hline & Insight** & \\
\hline & $\begin{array}{c}\text { Treatment } \\
\text { adherence*** }\end{array}$ & \\
\hline
\end{tabular}

$(-)$ signifies a reverse association. + to ${ }^{* * *}$, significance $\mathrm{p}<.10$ to $\mathrm{p}<.001$.

\section{Discussion}

It was rather easy to rate most of the EuRAX items with access to the comprehensive Swedish forensic assessments, and concurrent case history files of the hospital. Some EuRAX items require a face-to-face interview and were not rated for the present study. Therefore, only a subset of the EuRAX variables were analysed in this text; guided by two aims: to document the frequency of certain problems among the patients (low-level type of information), and to explore how much of this variance that could be captured by high-level constructs, among them four theoretically based criminological ones: Self-control, Attachment, Commitment and Compassion [15].

There was a high and sometimes extreme load with respect to many domains of relevance for health and social functions, and a marked clinical heterogeneity among the patients. It cannot be expected that their treatment needs can be covered by a limited set of remediation programs-treatment must be individualized. In order to do that, remediable problems must be identified and analysed with respect to generative mechanisms rather than as risk correlates $[10,11]$. Diagnoses or standard low-level criminological indices like age at 1st crime or number of previous sentences for life-time crimes and an array of similar conventional indices were not associated with the index crime. Another problem is that current risk instruments have little to offer in guiding clinical interventions, particularly for patients with psychoses, serious non-antisocial personality disorders, and "unique" risks Harris \& Rice [6].

The EuRAX indices appear to hold more promise with respect to prediction and are much more adapted to the clinical way of working with patients. The validity of the indices was estimated as the construct and discriminant validity, i.e., the strength of theoretically meaningful patterns of associations among variables measured in distinctively different ways. Of course, reliability as well as various kinds of validity must be further explored in future studies.

It is obvious that the pattern of EuRAX ratings conform to theoretical expectations of subjects with high scores on the $\mathrm{H}$ subscale of HCR-20 and PCL. Turning this argument upside down, many of the clinical variables, like social background, self-inflicted damage and suicide risk are not captured by these instruments, but are clinically important when assessing risk and formulating a treatment plan [35]. All the high-level criminological indices (Attachment, Commitment, Compassion and Self-control) delivered with respect to associations with HCR-15 and PCL. Evilness has never been studied empirically, except by the constructor of the Scale of Evil [36]. The current findings make it worthwhile to study the concept of Evil in more detail.

One virtue of the EuRAX approach is that it forces the clinician to collect complex information in a structured way-this in turn can be expected to improve clinical thinking and greatly improve communication among clinicians concerning patients (Coid, Ullrich et al, 2016). To some extent it is an issue of organizing low-level information in a theoretically meaningful way, as a complement to the tacit knowledge and clinical intuition that comes with experience. The EuRAX provides a set of high-level criminological indices, validated beyond doubt in the integrated theory of crime which we applied but to our knowledge not implemented in any current risk instrument. The analysis of the four high-level criminological concepts: self-control, attachment, commitment and compassion demonstrated the power of this approach as predictors of PCL and HCR-15 scores [15,37].

Summing up, the old (before 1970) clinical risk assessments were adapted to the use in the clinic but failed with respect to lack of structure and the presence of idiosyncrasies and failed completely in the legal context. Identification of this failure led to a loss of credibility of clinical assessments, also clinically. In an attempt to regain credibility, new risk assessment methods, developed for legal purposes (maximize prediction) were imported to the clinic, in spite of being alien to the way clinicians think and act. By now we realize that these legally based risk assessments will probably never work well enough even in legal settings, and certainly not in the clinic. What we need in the clinic is more of structured methods and a renaissance for causal thinking [12], in combination with the old and well-proven approaches, including idiographic data, tacit knowledge and clinical intuition [38]. Risk assessment should be integrated in a continuous stream of assessments of many other relevant attributes, individual as well as contextual, governing the kind and timing of treatment interventions. To this process should be added a parallel line of monitoring the outcome of the interventions verifying that a "small steps in the right direction" strategy brings us successively closer to the often distant goal (we rarely "cure" psychiatric patients) [8].

A risk assessment and the formulation of a treatment plan should start by applying a Structured Professional Assessment Tool. Are clinicians able to comprehend and use the extensive information inherent in a EuRAX assessment in order to produce better risk assessments/treatment plans? Probably, but that remains to be demonstrated empirically. The actual findings should be regarded as provisional and in need of cross validation. The main conclusion is one of promise-it appears worthwhile to proceed with the EuRAX approach. 


\section{Limitations}

One limitation of the present study is inherent in the selection of patients: one clinical unit, a stratified inclusion of patients in order to get enough $\mathrm{N}$ for the analysis of fairly rare crimes (arson, various sexual crimes), and the distribution of patients generated by pre-trial assessments. The definition of "serious mental disorder" by Swedish law is unique in the world. The virtue, in the present context, is that individuals with a wide range of psychiatric problems are assessed in-depth, including rather typical career criminals.

Another limitation is that only one assessor did the ratings. It is quite possible that some of the associations among the variables reflect halo effects present only in the mind of the assessor, not in the real world. Two arguments speak against that. The data on HCR15 and PCL were not available to the EuRAX assessor at the time of the assessment - and these data were collected by other assessors as part of the clinical routine. Still the associations are strong and clinically meaningful. The 139 patients were also rated according to the Scale of Evil by two independent assessors [36]. The inter-judge reliability was remarkably high: tau=.94 [35-47].

\section{References}

1. Webster CD, Eaves D, Douglas KS, Wintrup A (1995) The HCR-20 scheme: The assessment of dangerousness and risk. Vancouver 1995 Simon Fraser University and Forensic Psychiatric Services Commission of British Colombia, Canada.

2. Strand S, Belfrage H, Fransson G, Levander S (1999) Clinical and risk management factors in risk prediction of mentally disordered offendersmore important than historical data?: A retrospective study of 40 mentally disordered offenders assessed with the HCR-20 violence risk assessment scheme. Legal and criminological Psychology 4(1): 67-76

3. Hanson RK, Bourgon MKE (2009) The accuracy of recidivism risk assessments for sexual offenders: a meta-analysis of 118 prediction studies. Psychol Assessm 21(1): 1-21.

4. Yang M, Wong SC, Coid J (2010) The efficacy of violence prediction: a meta-analytic comparison of nine risk assessment tools. Psychol Bull 136(5): 740-767

5. Prell L, Vitacco MJ, Zavodny D (2016) Predicting violence and recidivism in a large sample of males on probation or parole. Int J Law Psychiatry 49(Pt A): 107-113

6. Harris G, Rice M (2015) Progress in violence risk assessment and communication: hypothesis vs evidence. Behav Sci Law 33(1): 128-145.

7. Rechenmacher J, Müller G, Abderhalden C, Schulc E (2014) The diagnostic efficiency of the extended German Brøset Violence Checklist to assess the risk of violence. Nurs Meas 22(2): 201-212.

8. Levander S, Munro J (2010) Tailoring treatment to the individual: schizophrenia and psychosis. Springer healthcare, London, England.

9. Dean K, Moran P, Fahy T, Tyrer P, Leese M, et al. (2007) Predictors of violent victimization amongst those with psychosis. Acta Psychiatr Scand 116(5): 345-353

10. Simpson AI, Grimbos T, Chan C, Penney SR (2015) Developmental typologies of serious mental illness and violence: Evidence from a forensic psychiatric setting. Aust N Z J Psychiatry 49(11): 1048-1059.

11. Dean K (2015) Exploring heterogeneity among mentally disordered offenders--The key to targeting Interventions (comment). Aust N Z Psychiatry 49(11): 1063-1064.
12. Wikström P0 (2011) Does everything matter? Addressing the problem of causation and explanation in the study of crime. In: when crime appears: The role of emergence, McGloin JM, Sullivan CJ, Kennedy LW (Eds.), Routledge: London, England.

13. Hirschi T (1969) Causes of delinquency, University of California Press, Berkeley, USA.

14. Gottfredson M, Hirschi T (1990) A general theory of crime. Stanford University Press, Stanford, CA1990, USA.

15. Wikström PO, Trieber K (2007) The role of self-control in crime causation: beyond Gottfredson and Hirschi's general theory of crime. European Journal of Criminology 4: 237-264.

16. Wikström PO (2014) Why crime happens: A situational action theory. In: Analytical Sociology: Actions and Networks, Manzo G (Ed.), Sussex: Wiley, USA, pp. 74-94

17. McKee SA, Harris GT, Rice ME (2007) Improving forensic tribunal decisions: the role of the clinician. Behav Sci Law 25(4): 485-506.

18. McDermott BE, Quanbeck CD, Busse D, Yastro K, Scott CL (2008) The accuracy of risk assessment instruments in the prediction of impulsive versus predatory aggression. Behav Sci Law 26(6): 759-777.

19. Buchanan A (2008) Risk of violence by psychiatric patients: beyond the "actuarial versus clinical" assessment debate. Psychiatr Serv 59(2): 184190.

20. Swanson JW (2008) Preventing the unpredicted: managing violence risk in mental health care. Psychiatr Serv 59(2): 191-193

21. Wolford G, Rosenberg SD, Rosenberg HJ, Swartz MS, Butterfield MI (2008) A clinical trial comparing interviewer and computer-assisted assessment among clients with severe mental illness. Psychiatr Sery 59(7): 769-775

22. Lindström E, Koernig T, Tuninger E, Levander S (2011) Development and validation of the Fast Assessment in Acute Treatment of PsychosisObservation Rating Scale (FAST-0). Int J Psychiatry Clin Pract 15(3): 180-195.

23. Pedersen LL, Rasmussen K, Elsass P (2010) Risk assessment: the value of structured professional judgments. International Journal of Forensic Mental Health 9(2): 74-81.

24. Greene JD (2015) The rise of moral cognition. Cognition 135: 39-42.

25. Cushman F, Kumar V, Railton P (2017) Moral Learning. Cognition 167: $1-282$

26. Svensson R, Pauwels L, Weerman FM (2010) Does the effect of selfcontrol on adolescent offending vary by level of morality? A test in three countries. Criminal Justice and Behavior 37(6): 732-743.

27. Ivert AK, Andersson F, Svensson R, Pauwels L, Levander TM (2018) An examination of the interaction between morality and self-contro in offending: A study of differences between girls and boys. Criminal Behavior and Mental Health.

28. Hodgins S, Tengstrom A, Eriksson A, Osterman R, Kronstrand R, et al. (2006) A multisite study of community treatment programs for mentally ill offenders with major mental disorders. Criminal Justice and Behavior 34(2): 211-228.

29. Stone MH (2010) Sexual sadism: a portrait of evil. J Am Acad Psychoanal Dyn Psychiatry 38(1): 133-157.

30. Murphy D (2007) Theory of mind functioning in mentally disordered offenders detained in high security psychiatric care: its relationship to clinical outcome, need and risk. Crim Behav Ment Health 17(5): 300-311.

31. Hare RD (1991) Manual for the hare psychopathy checklist-revised. Multi-Health Systems, Toronto, Canada.

32. Magidson J, Vermunt J (2004) Using latent GOLD 5.1 to estimate LC cluster models. 
33. Arseneault L, Moffit TE, Caspi A, Taylor A (2002) The targets of violence committed by young offenders with alcohol dependence, marijuana dependence and schizophrenia-spectrum disorders: findings from a birth cohort. Crim Behav Ment Health 12(2): 155-168.

34. Dalteg A, Lindgren M, Levander S (1990) Retrospectively rated ADHD is linked to specific personality characteristics and deviant alcohol reactions. J For Psychiat 10(3): 623-634

35. Witt K, van Dorn R, Fazel S (2013) Risk factors for violence in psychosis: systematic review and meta-regression analysis of 110 studies. PLoS One 8(2): e55942.

36. Stone MH (1989) Murder. Psychiatr Clin North Am 12(3): 643-651.

37. Wikström PO, vensson R (2010) When does self-control matter? The interaction between morality and self-control in crime causation. European Journal of Criminology 7(5): 1-16.

38. Kivisto AJ (2016) Violence risk assessment and management in outpatient clinical practice. J Clin Psychol 72(4): 329-349.

39. Lindström E, Olausson M, Persson B, Tuninger E, Levander S (2017) The Scale of Evil-interjudge reliability and associations with predictor variables. Int J of Forens Sci 2(1): 000118

reative Commons Attribution 4.0

International License

For possible submission use the below is the URL
40. Cooke DJ, Michie C (2009) Limitations

41. of diagnostic precision and predictive utility in the individual case: A challenge for forensic practice. Law Hum Behaviour 34(4): 259-274.

42. Gray NS, Taylor J, Snowden RJ (2008) Predicting violent reconvictions using the HCR-20. Br J Psychiat 192(5): 384-387.

43. Hart SD, Michie C, Cooke DJ (2007) Precision of actuarial risk assessment instruments: evaluating the "margins of error" of group v. individual predictions of violence. Br J Psychiat Suppl 49: s60-s65.

44. Leclerc B, Wortley R (2014) The reasoning criminal: Twenty-five years on. In: Cognition and crime: offender decision making and script analyses, Leclerc B, Wortley R (Eds.), Oxford, Routledge, UK, pp. 1-11.

45. Rice ME, Quinsey VL (2008) Shall evidence-based risk assessment be abandoned? Br J Psychiatry 192(2): 154

46. Litwack TL (1993) On the ethics of dangerousness assessments. Law Hum Behav 17(4): 479-482.

47. Steadman HJ, Cocozza JJ (1974) Careers of the criminally insane: Excessive social control of deviance. Lexington books, Lexington, MA.

Your subsequent submission with Crimson Publishers will attain the below benefits

- High-level peer review and editorial services

- Freely accessible online immediately upon publication

- Authors retain the copyright to their work

- Licensing it under a Creative Commons license

- Visibility through different online platforms

- Global attainment for your research

- Article availability in different formats (Pdf, E-pub, Full Text)

- Endless customer service

- Reasonable Membership services

- Reprints availability upon request

- One step article tracking system 